\title{
Personalized Psychiatry and Neurology
}

Article

\section{Clinical and genetic characteristics of juvenile myoclonic epilepsy}

\author{
Olga S. Shilkina, Svetlana N. Zobova, Ekaterina A. Domoratskaya , Diana V. Dmitrenko \\ V.F. Voino-Yasenetsky Krasnoyarsk State Medical University, 660022 Krasnoyarsk, Russia; olgabbn@mail.ru \\ (O.S.S.), snzobova80@gmail.com (S.N.Z.), e.domorats@yandex.ru (E.A.D.), mart2802@yandex.ru (D.V.D.), \\ * Correspondence: olgabbn@mail.ru; Tel.: +79504200830 (O.S.S.).
}

Citation: Shilkina, O.S.; Zobova, S.N.; Domoratskaya, E.A.; Dmitrenko, D.V. Clinical and genetic characteristics of juvenile myoclonic epilepsy. Personalized Psychiatry and Neurology 2021, 1 (2): 95-105. https://doi.org/10.52667/2712-91792021-1-2-95-105

Chief Editor: Nikolaj G. Neznanov, D Med Sci, Professor

Received: 29 October 2021

Accepted: 10 November 2021

Published: 15 November 2021

Publisher's Note: V.M. Bekhterev NMRC PN stays neutral with regard to jurisdictional claims in published maps and institutional affiliations.

Copyright: $@ 2021$ by the authors.

\begin{abstract}
Juvenile myoclonic epilepsy (JME) is reported as a clinically and genetically heterogeneous disease with a high risk of inheritance. The aim of the study was to establish phenotype features and genetic risk factors for juvenile myoclonic epilepsy to advance existing approaches of prevention, treatment, and observation of patients with JME. Methods: anamnestic; clinical; neurophysiological (EEG); neuroradiological (MRI), neuropsychological; laboratory (DNA-diagnostics). JME starts with absences more frequently in females as compared to males ( $32.0 \%$ vs. $15.4 \%$ ), and with GTCS and myoclonic in males as compared to females $(46.2 \%$ and $36.5 \%$ vs. $36.0 \%$ and $31.2 \%$, respectively). The 1st phenotype of JME was more frequently encountered in male individuals in comparison with female ones (55.8\% vs. $34.7 \%$ ), and the 2 nd phenotype was more frequently encountered in female individuals in comparison with male ones ( $16.9 \%$ vs. $5.8 \%)$. Homozygous carriage of the T allele of the GJD2 gene (rs3743123) was associated with the development of JME in the study population, $\mathrm{OR}=2.66$ (95\% CI 1.24 to 5.74$) .41 .5 \%$ of patients with JME have a slow metabolizer pharmacogenetic status, which is a risk factor for pseudo-pharmacoresistance and the development of adverse drug reactions.
\end{abstract}

Keywords: juvenile myoclonic epilepsy; phenotype; neuropsychological testing; rs206787; rs516535; BRD2 gene; Cx-36 (GJD2) gene; pharmacogenetic profile.

\section{Introduction}

The share of juvenile myoclonic epilepsy (JME) is 5-10\% of all cases of epilepsy in children and adolescents and $20-27 \%$ of all forms of genetic generalized epilepsy (GGE) [1-6]. Despite the fact, that pharmacy induced remission is achieved in $80-90 \%$ of cases of JME, the recurrence rate associated with withdrawal of antiepileptic drugs (AEDs) is still high. This is a socially and clinically significant feature of epilepsy and a concern of modern neurology, despite the emergence of new AED generations [7-9]. Genetic aspects of the disease are currently insufficiently studied. [10].

At the beginning of the 20th century, mutations in genes associated with mono-genic forms of JME and single nucleotide variants (SNVs) associated with an increase in the risk of JME were identified $[1,2,11]$. It is believed that the carriage of the variant of one of the Mendelian genes is enough to inherit a particular phenotype of JME [12]. Two-focal coding of JME with non-Mendelian inheritance type is assumed [13]. Currently, 9 chromosomal loci associated with JME are identified (Mendelian Inheritance in Man - OMIM, 2017) [14]. In some publications, 11 JME-associated loci are mentioned [12], but not in all of that genes are identified and not for all of them the type of inheritance is specified. Variable phenotypes of JME are also genetically determined [15]. The combination of predisposition gene variants can determine the type of JME course and its evolution. Thus, JME is reported as a clinically and genetically heterogeneous disease with a high risk of inheritance. All of the above explains the relevance of the present study. 


\section{Objective}

The aim of the study was to establish phenotype features and genetic risk factors for juvenile myoclonic epilepsy to advance existing approaches of prevention, treatment, and observation of patients with JME from the perspective of personalized medicine. The objectives of the study were: to analyze the frequency of JME phenotypes; to analyze the association of such SNVs as rs206787, rs516535 BRD2, rs3743123 of the GJD2 gene with JME; to investigate pharmacogenetic and pharmacokinetic profiles in the patients with JME by the example of the SNVs of the CYP2C9*2 and CYP2C9*3 carriage in the CYP2C9 gene coding the isozyme $2 \mathrm{~S} 9$ of liver's cytochrome P450.

\section{Materials and Methods}

The study was conducted at the Department of Medical Genetics and Clinical Neurophysiology of V.F. Voino-Yasenetsky Krasnoyarsk State Medical University as part of comprehensive research on the subject №. 210-16 "Epidemiological, genetic and neurophysiological aspects of the nervous system (central, peripheral and autonomic) and preventive medicine", registration number 0120.0807480 .

Clinical and laboratory examinations were performed in 2015-2018 on the basis of the neurological center of epileptology, neurogenetics, and brain research of the University Clinic (NC UC). Molecular genetic studies were performed on the basis of the Interdepartmental Research Laboratory of Medical Genetics at V.F. Voino-Yasenetsky Krasnoyarsk State Medical University. Clinical exome sequencing was performed on the basis of the Forest Genomics Laboratory of the Institute of Fundamental Biology and Biotechnology at the Siberian Federal University.

The study was approved by the Ethical Committee of V.F. Voino-Yasenetsky Krasnoyarsk State Medical University (protocol №65/2015 dated 11.11.2015). Adults and legal representatives of children included in the study had signed voluntary informed consent to process personal data and conduct all stages of the study.

The main group (177 patients with JME (male 29.4\%, female $70.6 \%$ ), mean age 27.74 \pm 0.62 years, Me 27.0 (22.0: 33.0) years. Inclusion criteria: patients with JME; residents of the Siberian Federal District; compliance with the study protocol. Exclusion criteria: other forms of epilepsy; residents of other regions of the Russian Federation; low compliance of patients or their legal representatives to the study protocol. The control group (150 healthy volunteers, age and gender comparable to patients in the main group, $p>0.05$ ). Inclusion criteria: healthy subjects; residents of the Siberian Federal District; compliance with the study protocol. Exclusion criteria: epilepsy; residents of other regions of the Russian Federation; low compliance with the study protocol. Stages of the study: retrospective analysis of outpatient records (according to NC UC, 2003-2018); prospective observation and examination of patients with JME (2015-2018); statistical processing and analysis of the results.

Research methods: anamnestic; clinical (examination of somatic and neurological statuses), clinical and genealogical; neurophysiological (EEG video monitoring); neuroradiological (MRI of the brain according to epilepsy protocol), neuropsychological (Beck Depression Scale, V.A. Braitwaite emotional excitability scale, modified by A.A. Rukavishnikov, "Selfassessment of anxiety, frustration, aggressiveness and rigidity" scale; methodology "Memory for numbers", "Schulte-Platonov red-black tables", "Kraepelin tables"), laboratory (DNA-diagnostics, therapeutic drug monitoring). Determination of the rs206787 and rs516535 of the BRD2 gene on chromosome 6p21 and rs3743123123 of the GJD gene on chromosome 15q14, the SNVs I359L (*3) A>C and R144C (*2) C > T of the CYP2C9 gene was performed by PCR-RT (Rotor-Gene 6000, Australia) using TaqMan 
technology and fluorescent probes (Applied Biosystems, USA). The library for the Clinical Exome study was prepared using the Clinical Exome Solution by SOPHiA GENETICS for Illumina MiSeq kit (Switzerland). Library amplification was performed using the KAPA HiFi Library Amplification Kit (USA). DNA quality was analyzed by the High Sensitivity DNA Kit by the Bioanalyzer 2100 electrophoretic system (Agilent Technologies, USA). To start the sequencer, MiSeq used the set "MiSeq Reagent Kit v2 (300-cycles)" (MS-102-2002, Illumina, USA).

Statistical methods. For database building the MS Excel 2013 was used; the analysis was performed using SPSS Statistics (Version 22.0) and the online calculator "Gene Expert" (http://geexp.ru/calculator_or.php). The distribution of genotypes was checked for Hardy-Weinberg equilibrium. In the pairwise comparison of genotype frequencies, $\chi 2$ criterion was used. The risk of JME was assessed by odds ratios (OR, 95\% CI). For parametric indicators mean, error of mean, median, and interquartile range Q25: Q75 were calculated; for nonparametric indicators proportion and error of proportion were calculated. Intergroup differences were considered statistically significant at $p<0.05$. If expected frequencies were less than 5, Fisher's exact test was used and considered statistically significant at $\mathrm{p}<0.05$.

\section{Results}

$$
\text { epilepsy }
$$

4.1. Frequency of occurrence and peculiarities of clinical phenotypes of juvenile myoclonic

The average age of patients with JME is $27.74 \pm 0.62$ years, Me 27.0 (22.0: 33.0) years. Distribution of patients by sex and age: males - 52 (29.4\%), average age $26.3 \pm 1.14$ years; females - $125(70.6 \%)$, average age $28.36 \pm 0.74$ years. The ratio of males to females is $1: 2.4$. The average age of onset of JME is $13.52 \pm 0.38$ years, including: males $-14.16 \pm 0.53$ years old, females $-13.25 \pm 0.48$ years (Table 1 ).

Table 1. The distribution of patients with JME by sex and age (in years)

\begin{tabular}{ccccc}
\hline $\begin{array}{c}\text { Characteristics } \\
\text { samples }\end{array}$ & $\begin{array}{c}\text { Average age, } \\
\mathbf{M} \pm \mathbf{m}\end{array}$ & $\begin{array}{c}\text { Me } \\
(\mathbf{Q} 25: \mathbf{Q} 75)\end{array}$ & $\begin{array}{c}\text { Averaje age of onset } \\
\text { of JME, } \\
\mathbf{M} \pm \mathbf{m}\end{array}$ & $\begin{array}{c}\text { Median of age of onset } \\
\text { of JME, } \\
\text { Me (Q25: Q75) }\end{array}$ \\
\hline Total & $27,74 \pm 0,62$ & $27,0(22,0: 33,0)$ & $13,52 \pm 0,38$ & $14,0(11,0: 16,0)$ \\
Male, $\mathrm{n}=52$ & $26,3 \pm 1,14$ & $24,0(20,0: 32,3)$ & $14,16 \pm 0,53$ & $14,0(12,0: 16,0)$ \\
& $\mathrm{p}=0,131$ & $\mathrm{p}=0,205$ & \\
Female, $\mathrm{n}=125$ & $28,36 \pm 0,74$ & $28,0(22,0: 33,0)$ & $13,25 \pm 0,48$ & $13,0(10,0: 16,0)$ \\
& $\mathrm{p}=0,131$ & & $\mathrm{p}=0,205$ & \\
\hline
\end{tabular}

Note. Differences in the studied indicators were calculated using Student's test.

Analysis of seizure onset characteristics with regard to patient gender showed that in females, JME was statistically significantly more often onset with absences $(32.0 \%$ vs. $15.4 \%, \mathrm{p}<0.05$ ), and in males, with generalized tonic-clonic seizure (GTCS) and myoclonic (46.2\% and $36.5 \%$ vs. $36.0 \%$ and $31.2 \%$ in females). Mean age at onset of GTCS was $15.8 \pm$ 0.36 years, including $15.8 \pm 0.69$ years for males and $15.8 \pm 0.42$ years for females, $p>0.05$ (Figure 1). 


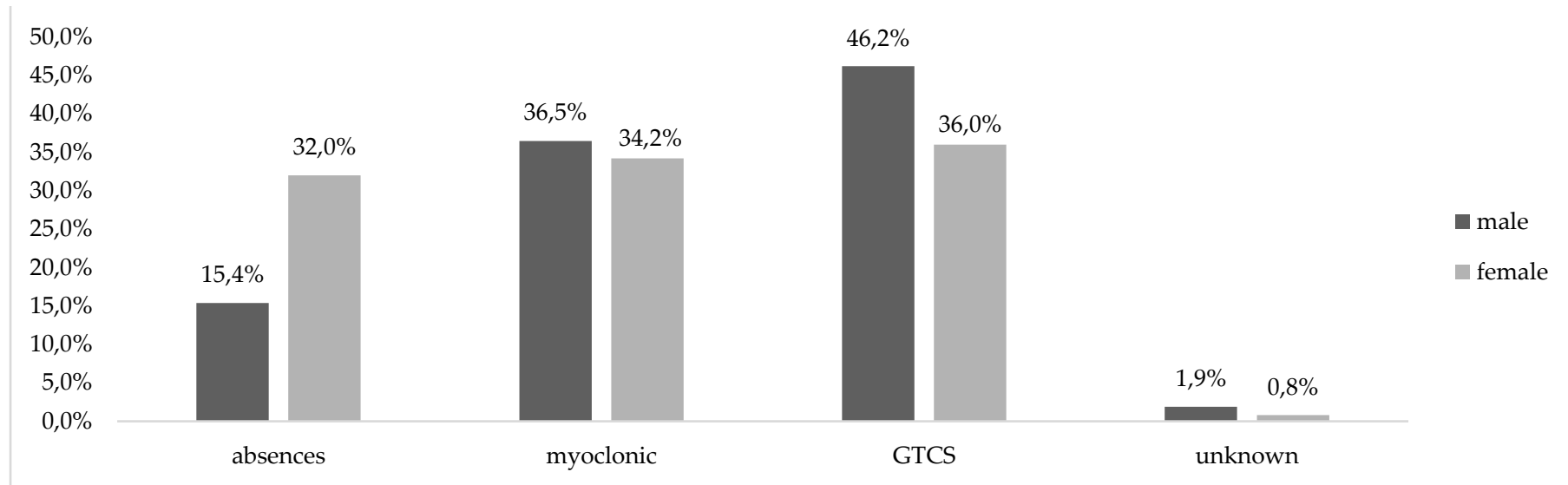

Figure 1. Seizure onset in patients with juvenile myoclonic epilepsy distributed by patients' gender

Analysis of JME phenotypes showed that the 1st (classical) phenotype was statistically significantly more frequent in male vs. female patients (55.8\% vs. $34.4 \%, \mathrm{p}<0.05)$. The most unfavorable in terms of achieving remission, the 2nd and 3rd phenotypes of JME were 2.8 and 2.9 times more common in females vs. males (5.8\% versus $16.1 \%$ and $5.8 \%$ versus $16.9 \%$, respectively), with the 2 nd phenotype being statistically significantly more prevalent in females $(\mathrm{p}<0.05)$ (Table 2$)$.

Table 2. Influence of patient gender on the JME phenotypes, $\mathrm{n}(\%)$

\begin{tabular}{ccccc}
\hline JME phenotype & $\begin{array}{c}\text { Total } \\
\mathbf{N = 1 7 7}\end{array}$ & $\begin{array}{c}\text { Male } \\
\mathbf{n 1 = 5 2}\end{array}$ & $\begin{array}{c}\text { Female } \\
\mathbf{n 2 = 1 2 5}\end{array}$ & $\mathbf{p}\left(\mathbf{\chi}^{\mathbf{2})}\right.$ \\
\hline I type & $72(40,7)$ & $29(55,8)$ & $43(34,4)$ & $\mathrm{p} 3,4=0,009^{*}$ \\
II type & $25(14,1)$ & $3(5,8)$ & $22(17,6)$ & $\mathrm{p} 3,4=0,04^{*}$ \\
III type & $23(12,9)$ & $3(5,8)$ & $20(16)$ & $\mathrm{p} 3,4=0,044$ \\
IV type & $57(32,2)$ & $17(32,7)$ & $40(32)$ & $\mathrm{p} 3,4=0,929$ \\
\hline
\end{tabular}

Note. *Statistically significant intergroup differences among males and females $(\mathrm{p}<0,05)$

In 93 (48.9\%) cases remission against the background of AEP hasn't been achieved; remission of GTCS and myoclonic seizures has been achieved in $43(22.6 \%)$, remission of GTCS, myoclonic seizures, and absences has been achieved in 39 (20.5\%). The 2nd phenotype of JME was the most unfavorable in terms of achieving remission, $p<0,05$ (Table 3).

Table 3 Frequency of remission in JME (per 100 patients)

\begin{tabular}{ccccc}
\hline Remisson & $\begin{array}{c}\text { Remission hasn't } \\
\text { been achieved }\end{array}$ & Seizure remission & Seizure and EEG remission & $\mathbf{p}(\chi 2)$ \\
\hline $\begin{array}{c}\text { Total, } \\
\mathrm{n}=175\end{array}$ & $93(53,1)$ & $43(24,6)$ & $39(22,1)$ & \\
$\begin{array}{r}\text { I type, } \\
\mathrm{n}=71\end{array}$ & $41(57,8)$ & $14(19,7)$ & $16(22,5)$ & $\mathrm{p}=0,444$ \\
$\begin{array}{c}\mathrm{II} \text { type, } \\
\mathrm{n}=25\end{array}$ & $14(56)$ & $10(40)$ & $1(0,4)$ & $\mathrm{p}=0,027^{*}$ \\
$\begin{array}{c}\text { III type, } \\
\mathrm{n}=23\end{array}$ & $11(47,8)$ & $7(30,4)$ & $5(21,7)$ & $\mathrm{p}=0,774$ \\
$\begin{array}{c}\text { IV type, } \\
\mathrm{n}=56\end{array}$ & $27(48,2)$ & $12(21,4)$ & $17(30,4)$ & $\mathrm{p}=0,211$ \\
\hline
\end{tabular}

Note. *Statistically significant intergroup differences $(p<0,05)$ 
A typical EEG pattern was registered in 81 patients (45.8\%); a combination of a typical pattern with at least one atypical pattern was registered in 96 patients $(54.2 \%)$.

\subsection{Neuropsychological testing of patients with juvenile myoclonic epilepsy}

The sub-sample of 64 people was divided into 2 groups: the main group - 32 (50\%) patients with JME and without adverse reactions on the background of AEP administration; the control group - $32(50 \%)$ healthy volunteers. The mean age in the main group was $25.9 \pm 1.4$ years, in the control group $-23.53 \pm 0.4$ years $(p=0.117)$.

The V.A. Braitwaite scale, used for assessing emotional excitability included four sections: general emotionality, anger, timidity, and lack of emotional control. Average score in the main group: male $-36.75 \pm 2.86$, $(4-5$, tendency to moderate emotional arousal); female - $47.3 \pm 2.35$, (5-6, medium emotional excitability); in the control group: male - 36.73 \pm 2.88 , female $-38,71 \pm 1,39$ (4, tendency to low emotional excitability). The main group significantly increased the level of neuroticism compared to the control group, $\mathrm{p}<0.05$.

Results for anxiety testing score with the C.D. Spielberger questionnaire: mean ST score in the main group and control groups was $38.31 \pm 1.37$ and $34.81 \pm 1.29$, respectively ( $p>0.05)$; mean LT score $43.72 \pm 1.72$ vs. $37.44 \pm 1.58$ ( $p<0.05)$.

The total score for results of methodology for the diagnosis of self-assessment of mental states, interpreted as a measure of overall LT, was $112.47 \pm 2.74$ in the main group, vs. $108.91 \pm 2.49$ in the control group ( $p>0.05$ ). The total score on the A.T. Beck questionnaire in the main group was $10.06 \pm 1.79$, corresponding to moderately severe depression; in the control group, $3.97 \pm 0.68$ (no depressive symptoms), $\mathrm{p}<0.05$. In the main group: on the cognitive-affective scale, $7.25 \pm 1.27$ (moderate severity of symptoms), in the control group, $2.78 \pm 0.529$ (normal); score on the somatization scale in the main group, $2.81 \pm 0.66$, (borderline normal) versus $1.38 \pm 0.28$ in the control group (normal), $\mathrm{p}>0.05$.

The mean number of correct answers on the "Number Memory" scale in the main group was $7.44 \pm 0.32$, mean score $-4 \pm 0.135$; in the control group $8.56 \pm 0.291$ and $4.44 \pm$ 0.127 respectively $(p<0.05)$, that is, in both groups the effectiveness of short-term memory was optimal, but statistically significantly lower in the JME group. Stability of attention according to Schulte tables technique, in the main and control groups were statistically insignificant $(p>0.05)$. The average coefficient of mental performance according to Krepelin's technique in the main group was $1.137 \pm 0.06$, in the control group $-1.072 \pm$ 0.018 , which corresponded to the norm, $\mathrm{p}=0.303$. But $19(59.4 \%)$ patients with JME had an irregular work capacity graph (a sign of emotional tension) against $7(21.9 \%)$ healthy volunteers $(\mathrm{p}<0.05)$.

\subsection{Genetics of juvenile myoclonic epilepsy}

Sequencing was performed in 4 patients with JME (Table 4).

It was expected that mutations at a specific locus of JME would be detected, but in all cases the disease was polygenic, as SNVs associated with JME and other generalized genetic epilepsies, including highly pathogenic ones, were identified. In a patient with JME code 86, $5 \mathrm{SNVs}$ with an established highly pathogenic effect were identified: $2 \mathrm{SNVs}$ in the EFHC1 gene (locus EJM1), $1 \mathrm{SNV}$ in the CHRNA4 gene (locus EJM2), 2 SNVs in the $B R D 2$ gene (locus EJM3), and $10 \mathrm{SNVs}$ with unspecified significance in loci associated with the development of JME were identified. In a patient with JME code 87, 4 pathogenic mutations were identified: in the EFHC1 (locus EJM1), BRD2 (locus EJM3), GABRD (locus EJM7), CLCN2 (locus EJM8) genes, as well as 11 SNVs of unspecified significance in EJM loci. In a patient with code $69 \mathrm{JME}, 4$ pathogenic SNVs in the EFHC1 (locus EJM1), BRD2 (locus EJM3), and JRK2 genes, as well as $8 \mathrm{SNVs}$ with unspecified significance were identified. In a patient with JME code 71, 2 pathogenic SNVs in the EFHC1 gene (EJM1 locus) 
and $11 \mathrm{SNVs}$ with unspecified significance were identified. DNA sequencing of patients with JME confirms the polygenic nature of the disease, which complicates clinical interpretation of sequencing results in burdened families and determination of the risk of disease transmission to offspring.

Table 4. Characteristics of patients with JME

\begin{tabular}{|c|c|c|c|c|}
\hline $\begin{array}{c}\text { Patient } \\
\text { code }\end{array}$ & $86 \mathrm{JME}$ & $87 \mathrm{JME}$ & $69 \mathrm{JME}$ & $71 \mathrm{JME}$ \\
\hline Date of birth & 11.06.1999 & 30.12.1997 & 07.10 .1997 & 11.02.1997 \\
\hline Sex & Female & Male & Male & Male \\
\hline Onset age (years) & 8 & 12 & 14 & 15 \\
\hline Onset & Absenses & Myoclonic & Myoclonic & GTCS \\
\hline JME phenotype & 2 & 1 & 1 & 1 \\
\hline Onset of GTCS & 12 & 14 & 15 & 15 \\
\hline Photosensitivity & + & - & + & + \\
\hline $\begin{array}{l}\text { Heredity for } \\
\text { epilepsy }\end{array}$ & Not burdened & $\begin{array}{c}\text { Burdened } \\
\text { (father's side) }\end{array}$ & $\begin{array}{c}\text { Burdened } \\
\text { (father's side) }\end{array}$ & Not burdened \\
\hline MRI & $\begin{array}{c}\text { Pituitary } \\
\text { microadenoma }\end{array}$ & No pathology & $\begin{array}{c}\text { Wasn't } \\
\text { performed }\end{array}$ & $\begin{array}{l}\text { Lateroventricular } \\
\text { asymmetry }\end{array}$ \\
\hline $\begin{array}{l}\text { Interictal EEG. (typical } \\
\text { patterns) }\end{array}$ & $\begin{array}{c}\text { Diffuse spike-poly- } \\
\text { spike waves } \\
3.5-4 \mathrm{~Hz}\end{array}$ & $\begin{array}{c}\text { Diffuse polyspike } \\
\text { waves } \\
3.5 \mathrm{~Hz}\end{array}$ & $\begin{array}{c}\text { Generalized spike- } \\
\text { polyspike waves } \\
3.5-4 \mathrm{~Hz}\end{array}$ & $\begin{array}{c}\text { Diffuse polyspike } \\
\text { waves } \\
3.5-4 \mathrm{~Hz}\end{array}$ \\
\hline $\begin{array}{l}\text { Interictal EEG. (atypi- } \\
\text { cal interictal patterns) }\end{array}$ & $\begin{array}{l}\text { Interhemispheric } \\
\text { asymmetry of dis- } \\
\text { charges; focal dis- } \\
\text { charges }\end{array}$ & $\begin{array}{l}\text { Interhemispheric } \\
\text { asymmetry of dis- } \\
\text { charges }\end{array}$ & $\begin{array}{c}\text { Interhemispheric } \\
\text { asymmetry of dis- } \\
\text { charges }\end{array}$ & $\begin{array}{l}\text { Focal initiation of dis- } \\
\text { charges; } \\
\text { generalized paroxys- } \\
\text { mal fast rhythm }\end{array}$ \\
\hline
\end{tabular}

Clinical and genealogical analysis showed unburdened heredity in $62.7 \%$ of patients with JME; in $8.5 \%$ - burdened heredity (by father's side); in 9.6\% - by mother's side; 1.1 both by father's and mother's sides, $18.1 \%$ - unknown; it was revealed that the 2nd phenotype of SME is associated with maternal transmission.

\subsubsection{The association of rs206787 and rs516535 of the BRD2 gene and juvenile myoclonic epilepsy}

The frequency of $B R D 2$ gene rs $206787 \mathrm{~T}$ allele carriage in the main group was $62.0 \%$, in the control group - $64.8 \%$ (OR $0.89 ; 95 \%$ CI 0.58 to $1.35 ; \mathrm{p}=0.58$ ); A allele in the main and control groups - $38 \%$ and $35.2 \%$ respectively (OR $1.13 ; 95 \%$ CI 0.74 to $1.74 ; \mathrm{p}=0.58$ ). The frequency of TT genotype carriage was $35.4 \%$ in the main group and $38.3 \%$ in the control group; AT genotype was $53.2 \%$ in the main group and $53 \%$ in the control group ( $p>0.05)$; AA genotype was $11.4 \%$ in the main group and $8.7 \%$ in the control group. The frequency of $B R D 2$ gene $\mathrm{T}$ allele rs516535 carriage in the main group was $62 \%$, in the control group - $64.8 \%$ (OR $0.89 ; 95 \%$ CI 0.58 to 1.35 ); allele $\mathrm{C}$ in the study and control groups - 38\% and $35.2 \%$ respectively (OR $1.13 ; 95 \%$ CI 0.74 to 1.71 ). The incidence of TT genotype carriage was $35.4 \%$ in the main group and $38.3 \%$ in the control group; ST genotype was 
$53.2 \%$ in the main group and $53 \%$ in the control group; CC genotype was $11.4 \%$ in the main group and $8.7 \%$ in the control group $(p>0,05)$. No statistically significant differences in the incidence of both alleles $(\chi 2=0.31 ; \mathrm{p}=0.58)$ and genotypes $(\chi 2=0.45 ; \mathrm{p}=0.8)$ of SNV rs206787 and rs516535 of the BRD2 gene were revealed, but a full unequal linkage between loci was observed both in patients with JME and in healthy volunteers.

The frequency of haplotypes with AA genotypes of rs206787 and CC rs516535 in men with JME tended to increase in comparison to controls but without statistically significant gender differences $(p>0.05)$. No statistically significant intergroup differences $(p>0.05)$ were found in the study of gender differences in the carriage of SNV rs3743123123 of the GJD2 gene. No statistically significant association of the carriage of the examined BRD2 gene haplotypes with the phenotypes and MRI changes in patients with JME was revealed as well ( $p>0.05)$. The association of TT/TT haplotype carriage with photosensitivity was revealed in patients with JME (OR=3.6; 95\% CI 1.37 - 9.48; $\mathrm{p}=0.02)$. The carriage of the AT/CT haplotype had no statistically significant effect on photosensitivity $(\mathrm{OR}=0.47 ; 95 \%$ CI 0.19 to 1.17). Similar results were obtained for the AA/CC haplotype (OR $=0.32 ; 95 \%$ CI 0.06 - 1.65). No statistically significant gender differences were found in the frequency of photosensitivity and its association with the carriage of the studied BRD2 gene SNVs in patients with JME.

\subsubsection{The association of Cx-36 (GJD2) and juvenile myoclonic epilepsy.}

The frequency of allele $\mathrm{C}$ carriage in the main group was $58.2 \%$, in the control group - $66.7 \%$ (OR 0.7; $95 \%$ CI 0.47 - .04); allele T carriage in the main group - $41.8 \%$, in the control group - 33.3\% (OR 1.43; 95\% CI $0.96-2.13$ ). There were no statistically significant differences in allele carriage $(\chi 2=3.19 ; \mathrm{p}=0.07)$. The CC genotype was found in $38 \%$ of cases in the main group and in $42.7 \%$ of cases in the control group ( $p>0.05$ ); the CT genotype was found in $40.5 \%$ of cases in the main group and in $48 \%$ of cases in the control group; the TT genotype was found in $21.5 \%$ in the main group and in $9.3 \%$ in the control group ( $p=$ 0.04). The OR for the TT genotype was 2.66 (95\% CI 1.24 to 5.74), for the ST genotype 0.74 ( $95 \%$ CI 0.42 to 1.28 ), and for the CC genotype 0.82 (95\% CI 0.47 to 1.44 ). Homozygous carriage of T allele of GJD2 gene (rs3743123) was statistically significantly associated with the development of JME in the main group, OR $=2.66$ (95\% CI $1.24-5.74) ; p=0.04$. No statistically significant intergroup differences $(p>0.05)$ were detected in the study of gender-specific features of SNV rs3743123123 carriage of the GJD2 gene.

\subsubsection{The analysis of the pharmacogenetic profile of patients with juvenile myoclonic epilepsy}

DNA testing was performed for $53 / 177$ (30\%) patients: $58.5 \%$ were common metabolizers (CYP2C9*1/*1 genotype); $39.6 \%$ were slow metabolizers (CYP2C9*1/*2, CYP2C ${ }^{*} 1 / * 3$ genotypes); $1.9 \%$ were ultraslow metabolizers (CYP2C9*2/*2, CYP2C9*3/*3 or CYP2C $9^{*} 2 / * 3$ genotypes). Toxic levels of valproic acid in blood were recorded more frequently in slow metabolizers compared to common metabolizers $(40.9 \%$ vs. $12.9 \%$, p < $0,05)$ (Table 5).

This study identifies further prospects for the use of association genetic studies of rs206787 and rs516535 SNPs carriage of the BRD2 gene to identify groups of patients at high risk of photosensitivity and for the wider implementation of clinical exome sequencing to search for common haplotypes in different ethnic groups in Russian Federation. 
Table 5. Results of therapeutic drug monitoring (TDM) in patients with JME

\begin{tabular}{cccc}
\hline TDM Results & $\begin{array}{c}\text { Common } \\
\text { metabolizers, } \\
\mathbf{n = 3 1}\end{array}$ & $\begin{array}{c}\text { Slow } \\
\text { metabolizers, } \\
\mathbf{n = 2 2}\end{array}$ & $\begin{array}{c}\mathbf{p} \\
\text { (Fisher criterion) }\end{array}$ \\
\hline Valproic acid $<100 \mu \mathrm{g} / \mathrm{ml}$ & $25(80,6 \%)$ & $13(59,1 \%)$ & - \\
Valproic acid $>100 \mu \mathrm{g} / \mathrm{ml}$ & $4(12,9 \%)$ & $9(40,9 \%)$ & $\mathrm{p}<0,05^{*}$ \\
Unknown & $2(6,5 \%)$ & - & - \\
\hline
\end{tabular}

Note. *Statistically significant intergroup differences $(\mathrm{p}<0,05)$

\section{Discussion}

JME is a widespread form of GGE, which includes myoclonic seizures, sometimes other seizure types (generalized tonic-clonic seizures, absences), onset in adolescence, and typical EEG changes as generalized spike and polyspike waves $4-6 \mathrm{~Hz}$ discharges with a normal background EEG [16,17]. The age of onset of JME covers a wide range from 8 to 36 years of age, with a peak onset from 12 to 18 years of age $[4,5,18]$.

Despite the bright clinical picture, there are different variants of JME, which determine the formation of certain phenotypes based on 2 components - predisposition gene mutations and environmental factors. Nowadays, against the background of the rapid development of molecular genetics, there are many studies aimed at identifying the JME genetic predisposition. It was supposed that there were genes with Mendelian (monogenic type of inheritance), two-locus model of inheritance [19], but nowadays, JME is considered to be a multifactorial disease, which is also confirmed by our study of clinical sequencing. However, due to the small sample size, it is difficult to analyze the contribution of susceptibility gene mutations to the formation of any disease trait. However, there are prospects of this study in the future.

The results of the molecular-genetic study of the carriage of SNVs rs206787 and rs516535 of the BRD2 gene showed no connection to the development of JME in the studied population that is in agreement with the study carried out by D.K. Pal et al. in 2006 and Cavalleri G. et al. in 2013 [19-24]. However, these research groups have established an unbalanced linkage of the $B R D 2$ gene loci, which is also confirmed by our study.

In contrast to Lorenz S. et al. who established an association of the $6 \mathrm{SNVs}$ of the $B R D 2$ gene in the predisposition to a photoparoxysmal response, our data do not confirm the association of the carriers of the SNVs rs206787 and rs516535 of the BRD2 gene with photosensitivity in patients with JME, and also do not confirm the influence of this SNVs on the formation of certain phenotypes of JME and structural changes in the brain detected by MRI $[25,26]$.

We confirmed that homozygous carriage of T SNV of the Cx-36 gene (rs3743123) was associated with the development of JME in patients living in the Siberian Federal District. Also this SNVs are a risk factor for the development of JME, OR $=2.66$ (95\% CI 1.24-5.74); $\mathrm{p}=0.04$. A clinically significant association of these SNVs of the Cx-36 gene with the development of JME has also been previously demonstrated in two independent studies $[27,28]$.

In 2006, I. E. Martínez-Juárez et al. identified four phenotypes of JME: type 1 - the classic JME phenotype (72\%); type 2 - childhood absences epilepsy with transformation to JME (18\%); type 3 - JME with absences (7\%), and type 4 - JME with atonic seizures (3\%) $[15,29]$. Thus, type 1 - the classic phenotype of JME was the most common, which agrees with our data. Comparable data were obtained for 2 and 3 phenotypes of JME. In addition, we confirmed the data on the unfavorable prognosis in type 2 of JME with regard to achieving seizure and EEG remission, as well as maternal inheritance. 
Many researchers have described anxiety disorders as one of the features of JME [30-32]. Despite being aware of the factors that cause seizures, many patients cannot cope with their emotions independently. A decrease in stress tolerance leads to difficulties in falling asleep and, consequently, to such undesirable lack of sleep [33]. These disorders can be caused by concomitant non-psychotic psychiatric disorders, which are often described in JME. These include different types of anxiety and mood disorders: generalized anxiety disorder, phobias, depression, dysthymia, and psychosomatic disorders [34-36]. The data are consistent with ours: the incidence of depressive symptoms is higher in patients with JME compared to people without epilepsy.

The data on cognitive impairment in patients with JME are inconsistent - according to many authors, the presence of cognitive impairment is not typical for JME, but in general, epilepsy is often accompanied by cognitive impairment [11, 12, 37]. According to our data, the main indices of cognitive functions in patients with JME are lower than in those without JME but correspond to the normative ones.

The diagnosis of JME is often made late which leads to a significant reduction in the quality of life of patients [38]. According to our data, the diagnosis of JME was made after an average of 10.5 years, which is comparable with the findings of Panayiotopoulos S.P. et al. in 1992 [21, 39].

Thus, the literature review on the state of the JME problem indicates that this problem is far from being resolved. At the same time, in recent years the greatest interest of researchers is given to the issues of early diagnosis of the disease, especially in burdened families. It is believed that modification of the external trigger factors, which lead to severe seizures, their serial and status course, is an urgent problem of modern neurology.

\section{Conclusion}

The incidence of JME is lower among males than among females (ratio of males to females $1: 2.4)$. The average age at the onset of JME is $13.52 \pm 0.38$ years. The disease starts with absences more frequently in females as compared to males (32.0\% vs. $15.4 \%)$, and with GTCS and myoclonic in males as compared to females $(46.2 \%$ and $36.5 \%$ vs. $36.0 \%$ and $31.2 \%$, respectively). The 1st phenotype of JME was more frequently encountered in male individuals in comparison with female ones ( $55,8 \%$ vs. $34,7 \%)$, and the 2 nd phenotype was more frequently encountered in female individuals in comparison with male ones $(16,9 \%$ vs. $5,8 \%)$. The 2 nd phenotype of JME is characterized by a low frequency of achieving remission. The incidence of anxiety-depressive disorders is higher in patients with JME compared to those without JME.

JME is a polygenic disease, which limits the interpretation of sequencing results and screening for JME in burdened families. There is no association of carriage of the BRD2 rs206787 and rs516535 SNVs with the development of JME in the studied population. The association of TT/TT haplotype carriage of the SNVs rs206787 and rs516535 of gene BRD2 and photoparoxysmal reaction in patients with JME was revealed. Homozygous carriage of the T allele of the GJD2 gene (rs3743123) was associated with the development of JME in the study population, $\mathrm{OR}=2.66$ (95\% CI 1.24 to 5.74 ).

$41.5 \%$ of patients with JME have a slow metabolizer pharmacogenetic status, which is a risk factor for pseudopharmacoresistance and the development of adverse drug reactions.

Author Contributions: Conceptualization, D.V.D.; methodology, D.V.D.; validation O.S.S.; data processing, O.S.S.; investigation, O.S.S. and S.N.Z.; writing-original draft preparation, O.S.S.; writing - review and editing, O.S.S. and E.A.D.; project administration, D.V.D. All authors have read and agreed to the published version of the manuscript.

Funding: This research received no external funding.

Institutional Review Board Statement: The study was conducted according to the guidelines of the Declaration of Helsinki, and approved by the Ethics Committee of Krasnoyarsk State Medical University named after prof. V.F. Voino-Yasenetsky (protocol code №65/2015 dated 11.11.2015). 
Informed Consent Statement: Informed consent was obtained from all subjects involved in the study.

Conflicts of Interest: The authors declare no conflict of interest.

Sample Availability: Samples of the compounds are available from the authors.

Acknowledgments: The authors express their gratitude to Natalia A. Shnayder, Doctor of Medical Sciences, Professor, for her supervision of this article.

\section{References}

1. Karlov V.A., Freidkova N.V. Juvenile myoclonic epilepsy. In: Epilepsy in Children and Adult Women and Men. Ed. by V.A. Karlov. M.: Medicine, 2010; pp. 244-8.

2. Karlov V.A. Epilepsy in Children and Adults, Women and Men: Guidance for Physicians. - M.: Medicine, $2010 ; 720$ p.

3. Mukhin K.Y. Juvenile myoclonic epilepsy (Jantz syndrome). In: Idiopathic forms of epilepsy: systematics, diagnostics, therapy. Ed. by K.Y. Mukhin, A.S. Petrukhin. M.: Art-Business-Center, 2000; pp. 120-35.

4. Petrukhin A.S., Mukhin K.U., Kalinina L.V., Pylaeva O.A. Lamictal: poly- and monotherapy of epilepsy. Psychiatry and psychopharmacotherapy. 2004; appendix 1:20-26.

5. Petrukhin A.S., Kalinina L.V., Anpilogova I.E. Clinical and epidemiological characteristics of epilepsy in children living in the Tula region. Pediatrics. Speransky's Journal. 2004; 83(6):101-103.

6. Scheffer I.E., Berkovic S., Capovilla G., Connolly M.B., French J., Guilhoto L., Hirsch E., Jain S., Mathern G.W., Moshé S.L., Nordli D.R., Perucca E., Tomson T., Wiebe S., Zhang Y.H., Zuberi S.M. ILAE classification of the epilepsies: Position paper of the ILAE Commission for Classification and Terminology. Epilepsia. 2017 Apr;58(4):512-521. doi: 10.1111/epi.13709. Epub 2017 Mar 8

7. Mironov M.B. Risk factors and relapse rate in patients with juvenile forms of idiopathic generalized epilepsy. PhD dissertation. M., 2005; 119 p.

8. Mironov M.B., Mukhin K.Y., Petrukhin A.S., Kholin A.A. Control of treatment efficacy of patients with juvenile forms of idiopathic generalized epilepsy and "pseudoremission" state. Journal of Neurol Psychiatr 2005;105(8):24-8.

9. Mukhin K.Y., Mironov M.B., Glukhova L.Y. Clinical and electroencephalographic changes in juvenile myoclonic epilepsy. Russian journal of pediatric neurology. 2014; 3:30-35.

10. Belousova E. D. Genetics of epilepsy: why and how to examine children with epilepsy. Neurology, neuropsychiatry, psychosomatics. 2014; 6(1S):4-8.

11. Delgado-Escueta A.V., Koeleman B.P., Bailey J.N., et al. The quest for juvenile myoclonic epilepsy genes. Epilepsy Behav. 2013;28(1):52-57.

12. Delgado-Escueta A.V. Advances in genetics of juvenile myoclonic epilepsies. Epilepsy Curr. 2007; 7(3): 61-67.

13. Greenberg D.A., Stewart W.C. How should we be searching for genes for common epilepsy? A critique and a prescription. Epilepsia. 2012 Sep;53 Suppl 4:72-80. doi: 10.1111/j.1528-1167.2012.03616.x. Review.

14. Website Online Mendelian Inheritance in Man (OMIM); http://www.omim.org/

15. Martínez-Juárez I.E., Alonso M.E., Medina M.T., et al. Juvenile myoclonic epilepsy subsyndromes: family studies and long-term follow-up. Brain. 2006;129(5):1269-1280

16. Nasyrova R.F., Sivakova N.A., Lipatova L.V., et al. Biological markers of efficacy and safety of antiepileptic drugs: pharmacogenetics and pharmacokinetics. Siberian Medical Review. 2017; (103): 17-25.

17. Nordli D.R. Idiopathic generalized epilepsies officially recognized by the international anti-epilepsy league. International Journal of Neurology. 2008; 5: 121-135.

18. Nurmukhametova S.R., Magzhanov R.V. Clinical and epidemiological characteristics of epilepsy in Sterlitamak. Medical Vestnik of Bashkortostan. 2011;6(4):115.

19. Halasz P., Janszky J., Barcs G., Szucs A. Generalised paroxysmal fast activity (GPFA) is not always a sign of malignant epileptic encephalopathy. Seizure 2004;13:270-6

20. Cavalleri G. Haplotype mapping in epilepsy genetics and pharmacogenetics.: University College London; 2013.

21. Grünewald R.A., Chroni E., Panayiotopoulos C.P. Delayed diagnosis of juvenile myoclonic epilepsy. J Neurol Neurosurg Psychiatry 1992 Jun; 55(6): 497-499. PMCID: PMC1014908.

22. O'Muircheartaigh J., Vollmar C., Barker G.J., et al. Focal structural changes and cognitive dysfunction in juvenile myoclonic epilepsy. Neurology 2011;76:34-40.

23. Pal D.K., Durner M., Klotz I., et al. Complex inheritance and parent-of-origin effect in juvenile myoclonic epilepsy. Brain Dev. 2006;28:92-98

24. Pal D.K., Greenberg D.A. Major susceptibility genes for common idiopathic epilepsies: ELP4 in rolandic epilepsy and BRD2 in juvenile myoclonic epilepsy. In: Jasper's Basic Mechanisms of the Epilepsies. 4th ed; Ed. by Noebels J.L., Avoli M., Rogawski M.A., Olsen R.W., Delgado-Escueta A.V. Bethesda (MD): National Center for Biotechnology Information (US); 2012

25. Hantus S. Idiopathic generalized epilepsy syndromes of childhood and adolescence. In: Treatment of epilepsy, 5th ed; Ed. by Wyllie E. 2011:260-5. 
26. Lorenz S., Taylor K.P., Gehrmann A., et al. Association of BRD2 polymorphisms with photoparoxysmal response. Neurosci Lett 2006;400:135-139.

27. Hempelmann A., Heils A., Sander T. Confirmatory evidence for an association of the connexin-36 gene with juvenile myoclonic epilepsy. Epilepsy Res 2006;71:223-228.

28. Herpin, T. H. Des asces incomplets de l'epilepsie. J Balliere et Fils. 1867 p.

29. Bartolini E., Pesaresi I., Fabbri S., Cecchi P., Giorgi F.S., Sartucci F., Bonuccelli U., Cosottini M. Abnormal response to photic stimulation in juvenile myoclonic epilepsy: an EEG-fMRI study. Epilepsia. 2014 Jul;55(7):1038-47. doi: 10.1111/epi.12634. Epub 2014 May 23.

30. Holmes M.D., Brown M., Tucker D.M. Are “generalized” seizures truly generalized? Evidence of localized mesial frontal and frontopolar discharges in absence. Epilepsia 2004; 45:1568-1579.

31. Inoue M., Duysens J., Vossen J.M., Coenen A.M. Thalamic multipleunit activity underlying spike-wave discharges in anesthetized rats. Brain Res 1993; 612:35-40.

32. Jallon P., Loiseau P., Loiseau J. Newly diagnosed unprovokedepileptic seizures: presentation at diagnosis in CAROLE study. Coordination Active du Reseau Observatoire Longitudinal de l'Epilepsie. Epilepsia 2001;42:464-75.

33. Clemens B., Puskás S., Besenyei M., Spisák T., Opposits G., Hollódy K., Fogarasi A., Fekete I., Emri M. Neurophysiology of juvenile myoclonic epilepsy: EEG-based network and graph analysis of the interictal and immediate preictal states. Epilepsy Res. 2013 Oct;106(3):357-69. doi: 10.1016/j.eplepsyres.2013.06.017. Epub 2013 Jul 22.

34. Cohen B.H., Naviaux R.K. The clinical diagnosis of POLG disease and other mitochondrial DNA depletion disorders. Methods 2010; 5: 364-73. Doi: 10.1016/j.ymeth.2010.05.008. PMID: 20558295

35. Delgado-Escueta A.V., Enrile-Bacsal F. Juvenile myoclonic epilepsy of Janz. Neurology 1984;34:285-94.

36. Delgado-Escueta A.V., Greenberg D.A., et al. Mapping the gene for juvenile myoclonic epilepsy. Epilepsia 1989; $30: 8$-18.

37. Desai D., Desai S., Jani T. Juvenile Myoclonic Epilepsy in Rural Western India: Not Yet a Benign Syndrome. Epilepsy Res Treat. 2016:1435150. PMID: 27818795

38. Betting L.E., Mory S.B., Lopes-Cendes I., Li M., Guerreiro M.M., Cendes F. EEG features in idiopathic generalized epilepsy: clues to diagnosis. Epilepsia 2006;47:523-8.

39. Jallon, P. Epidemiology of idiopathic generalized epilepsies. Epilepsia 2005;46(9):10-4. 